\title{
RESEARCH
}

Open Access

\section{Knowledge and attitudes towards contraceptives among adolescents and young adults}

Aanchal Sharma ${ }^{1,2^{*}}$ (D, Edward McCabe ${ }^{3}$, Sona Jani ${ }^{3}$, Anthony Gonzalez ${ }^{4}$, Seleshi Demissie ${ }^{5}$ and April Lee ${ }^{3}$

\begin{abstract}
Background: Despite endorsements supporting the use of intrauterine devices (IUDs) for adolescents and young adult women (AYA), they have limited knowledge about them Male partners can influence contraceptive decisions, however their perceived knowledge about IUDs is lower than their objective knowledge. We aim to establish current AYA baseline contraceptive knowledge and attitudes so providers can better target their sexual health educational interventions.
\end{abstract}

Methods: Females and males, aged 13 to 23 years old, from our suburban adolescent clinic, completed an anonymous survey that assessed their knowledge and attitudes towards methods of contraception, with an emphasis on the IUD.

Results: Completed surveys totaled 130 (99 females/31 males). Demographic results revealed 31.3\% Black/AfricanAmerican, 30.5\% Latino/Hispanic, 17.6\% White, 3.0\% Asian, and 14.5\% Other. The majority of participants (80\%) were sexually active. The majority (69.5\%) stated they/their partner were currently using a contraceptive method; only $2.6 \%$ used IUDs. Half of females (56.6\%) and $10.1 \%$ of males had heard of IUDs. Despite this, male and female participants lacked knowledge regarding specific IUD facts. Of the participants who had used emergency contraception (EC), only 6.4\% knew the copper IUD could be used for EC.

Conclusion: Contraceptive knowledge deficits, especially regarding the IUD, continue to exist for AYA patients. Many participants stated they required EC despite "satisfaction" with their birth control method(s) and most were unaware that the copper IUD could be used as EC. These discrepancies highlight the importance of comprehensive contraceptive education for AYA patients. Enhanced and consistent contraceptive options counseling can help providers ensure that their AYA patients make well-informed decisions about family planning, thus improving their quality of life.

Keywords: Contraception, Reproduction, IUD, Sexual health, Adolescent health

\footnotetext{
* Correspondence: aanchal10@gmail.com

'Department of Pediatrics, Staten Island University Hospital, Staten Island, NY, USA

2Department of Developmental Medicine, Boston Childrens Hospital, Boston, MA, USA

Full list of author information is available at the end of the article
}

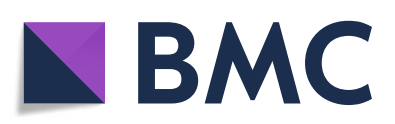

(c) The Author(s). 2021 Open Access This article is licensed under a Creative Commons Attribution 4.0 International License, which permits use, sharing, adaptation, distribution and reproduction in any medium or format, as long as you give appropriate credit to the original author(s) and the source, provide a link to the Creative Commons licence, and indicate if changes were made. The images or other third party material in this article are included in the article's Creative Commons licence, unless indicated otherwise in a credit line to the material. If material is not included in the article's Creative Commons licence and your intended use is not permitted by statutory regulation or exceeds the permitted use, you will need to obtain permission directly from the copyright holder. To view a copy of this licence, visit http://creativecommons.org/licenses/by/4.0/. The Creative Commons Public Domain Dedication waiver (http://creativecommons.org/publicdomain/zero/1.0/) applies to the data made available in this article, unless otherwise stated in a credit line to the data. 


\section{Plain English summary}

In this study, we demonstrate that barriers of access, awareness and knowledge continue to exist for adolescents and young adults (AYA) when it comes to contraception. Specifically, despite awareness about the intrauterine device (IUD), AYA lack adequate knowledge regarding its utility. The results of our study highlight the need for comprehensive contraception educational initiatives. For example, placing an IUD for emergency contraception could then additionally provide ongoing contraceptive benefits. Curricula that highlight the dual use of the IUD could help AYA see the short- and longterm benefits of using the IUD. This study assesses the baseline contraceptive knowledge and attitudes of AYA, which could inform and help healthcare providers tailor the sexual health education they provide their AYA patients. This would ultimately help AYA patients to overcome the barriers they face when choosing contraceptive methods that are best suited for them. This study affirms the current contraceptive knowledge and beliefs of AYA patients and serves as a jumping-off point for education and provision of contraceptive options counseling.

\section{Introduction/background}

The American College of Obstetrics and Gynecology (ACOG) has recommended intrauterine devices (IUDs) as first-line contraceptive choices for parous and nulliparous adolescents [1]. The American Academy of Pediatrics (AAP) endorses the use of IUDs as contraception to parous adolescents and to those who consistently protect themselves against sexually transmitted infections (STI) [2]. IUD use has increased over the past decade; however, overall U.S. IUD use remains low [3-5]. Copper IUDs can also function as emergency contraception (EC), yet its use as such remains limited [6]. Existing research has revealed that young women have limited knowledge about and access to IUDs [7]. Despite its effectiveness, overall use of IUDs in the U.S. remains low. Only $12 \%$ of current contraceptive users reported long-acting reversible contraception (LARC) use between 2011 and 2013 [8, 9]. Studies have explored the reasons for the continued low rate of use and insertion of the IUD in adolescents and young adults despite the recognition that the IUD is a safe and effective contraceptive method $[10,11]$.

Whitaker et al. found that only $40 \%$ of 144 female participants aged 14-24 had heard about IUDs; once educated, they began to think positively about IUDs [7]. However, awareness is not enough. In a 2012 study done by Barrett et al., they found that only $39.4 \%$ of subjects who had heard about the IUD were able to identify its features [12]. Awareness and perceived knowledge of IUDs among males is low in comparison to condoms and birth control pills [12]. Since male partners can influence the contraceptive decision-making process, it is important that studies are done to understand their perspectives.

This study aims to understand baseline contraceptive knowledge and attitudes of adolescents. This understanding will help healthcare providers improve sexual health education and overcome barriers faced by patients when choosing contraceptives methods that are best suited for them.

\section{Methods}

Subjects were recruited from Staten Island University Hospital's adolescent clinic. The study was offered to all patients in this clinical setting, which included male and female patients, aged 13 years old to 23 years old. The study was offered to all new and existing patients over a six-month period, from March 2018 to August 2018. Potential participants were provided with a written document containing information regarding the study and provided verbal consent if they chose to participate. They then completed a twenty-minute anonymous survey, written in English, that assessed their knowledge and overall attitudes towards different methods of contraception, with an emphasis on the IUD. Inclusion criteria consisted of age between 13 to 23 years old and the ability to read and comprehend in English.

The survey consisted of five questions regarding sexual history (including sexually transmitted infection history, pregnancy history, contraception use), three questions about emergency contraceptive use, a section on knowledge about birth control methods which consisted of yes/no and true/false/ "I don't know" questions, and a section on knowledge about the copper IUD which consisted of true/false/“I don't know" questions. The survey also included demographic questions regarding age, gender, educational level, race/ethnicity, and health insurance status.

The primary objective of this study was to determine adolescent and young adult knowledge of the copper intrauterine device (IUD) as a method of both emergency and long-acting contraceptive method. Assuming that the expected prevalence of knowledge of the copper IUD among adolescents aged 13 to 23 years old is 50\%, we estimated that a sample size of approximately 100 subjects would provide us with a two-sided 95\% confidence interval for the true prevalence that would extend $10 \%$ from the observed prevalence. Within this clinical setting, a total of 131 participants completed the survey. Of the completed surveys, 130 completed surveys met criteria for inclusion in this analysis. One subject was excluded because the participant's age was beyond the study's range.

The study design received Northwell Health Institutional Review Board approval prior to implementation. 
Participants provided verbal informed consent prior to completing the survey. Data collection involved investigators entering responses from completed surveys into a password-protected research database (REDCap). Only investigators listed on this study had access to the data.

\section{Statistical analysis}

Demographic and clinical characteristics for the study population were summarized using means with standard deviations for continuous variables and frequencies with percentages for categorical variables. Differences between groups in continuous variables were estimated with independent-sample $t$ test. For categorical variables, either Chi-square test or Fisher's exact test were used as appropriate. All tests were two-tailed and Differences were considered significant at $P<0.05$. All statistical analyses were performed using SAS software (Statistical Analysis Systems Inc., Cary, NC, USA) Version 9.3.

\section{Results}

There were 99 female participants (76.2\%) and 31 male participants $(23.8 \%)$. The mean age of participants was 18.3 years old. The majority $(65.3 \%)$ of respondents were aged $18-23$ years old and about one third $(34.7 \%)$ were aged 13-17 years old. A majority of respondents were either in high school (38.5\%) or college (44.3\%). Demographic results revealed 31.3\% Black/African-American, 30.5\% Latino/Hispanic, 17.6\% White, 3.0\% Asian, and $14.5 \%$ Other. A majority of respondents had health insurance, either private $(25.6 \%)$ or public $(40.2 \%)$.

The majority $(80 \%)$ of participants were sexually active. The majority $(82.8 \%)$ reported having partners of the opposite sex, $14.1 \%$ reported having with partners of the same sex, and 3.0\% reported having both partners of the same and opposite sex. Most (69.5\%) participants stated they or their partner were currently using a contraceptive method. Of those using birth control, 71\% used condoms, $38 \%$ used oral contraception pills (OCP), while only $2.6 \%$ used IUDs. Approximately one third (36.4\%) of total respondents reported a history of EC use by them or their partner(s). The majority $(90.5 \%)$ of total respondents reported no history of STIs and $90.4 \%$ reported no history of pregnancies in themselves or their partner(s).

Most of the participants surveyed were aware of contraceptive methods. Survey results indicated that $100 \%$ were aware of male condoms; $89.9 \%$ were aware of female condoms; $92.2 \%$ were aware of OCPs; $66.7 \%$ were aware of IUDs; $63.3 \%$ were aware of hormonal implants; $76.2 \%$ were aware of injectable contraceptive hormones; $72.1 \%$ were aware of hormonal vaginal rings; and $64.8 \%$ were aware of hormonal contraceptive patches. Of those who responded that they had heard of the IUD, 84.9\% were females and only $15.1 \%$ were males [Table 1 ]. Of
Table 1 Demographics by Awareness of IUDs ${ }^{a}$

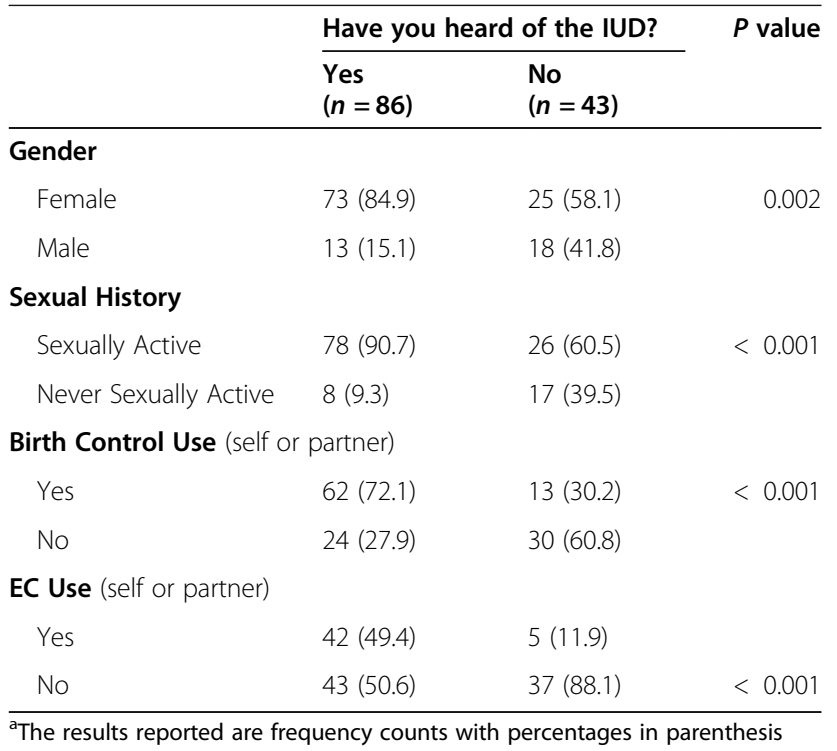

the participants who responded that they had heard of the IUD, $90.7 \%$ were sexually active, $72.1 \%$ stated that they themselves or their partner(s) were using a form of contraception, and $49.4 \%$ stated they or their partner(s) had used EC in the past $(p<0.001)$ (Table 1$)$.

Almost half (49.2\%) of participants who responded that they were satisfied with their method of birth control had used EC in the past $(p<0.001)$ (Table 2). Of those with a history of EC use by themselves or their partner(s), 83.0\% reported that they or their partner(s) were using a method of birth control $(p<0.001)$ (Table 3). Only $17.8 \%$ who reported a history of EC use knew the copper IUD could be used for EC $(p<0.001)$ (Table 3).

The awareness of the IUD was also specifically assessed by gender, sexual history, birth control use, and EC use. Of those who had heard of the IUD, 90.7\% reported history of sexual activity and $49.4 \%$ reported history of EC use by them or their partner(s) $(p<0.001)$ [Table 2]. Despite having heard of IUDs, both male and female participants lacked knowledge regarding the utility of the IUD, whether or not they were sexually active. (Table 4) Only $14.1 \%$ of those who had heard of the IUD knew that it could be used as EC $(p<0.001)$ (Table 4$)$.

Table 2 Satisfaction with Birth Control and Emergency Contraception (EC) Use ${ }^{a}$

\begin{tabular}{cllll}
\hline & \multicolumn{2}{l}{ Satisfaction with Birth Control } & P value \\
\cline { 2 - 4 } & $\begin{array}{l}\text { Yes } \\
(\boldsymbol{n}=\mathbf{5 9})\end{array}$ & $\begin{array}{l}\text { No } \\
(\mathbf{n}=\mathbf{8})\end{array}$ & $\begin{array}{l}\text { I am not using birth control } \\
(\boldsymbol{n}=\mathbf{6 1})\end{array}$ & \\
\hline History of EC Use (self or partner) & $<0.001$ \\
Yes & $29(49.2)$ & $6(75.0)$ & $11(18.0)$ & \\
No & $30(50.8)$ & $2(25.0)$ & $50(82.0)$ & \\
\hline
\end{tabular}

${ }^{\mathrm{a}}$ The results reported are frequency counts with percentages in parenthesis 
Table 3 History of Emergency Contraception (EC) Use ${ }^{a}$

\begin{tabular}{|c|c|c|c|}
\hline & \multicolumn{2}{|c|}{ History of EC Use (self or partner) } & \multirow[t]{2}{*}{$P$ value } \\
\hline & $\begin{array}{l}\text { Yes } \\
(n=47)\end{array}$ & $\begin{array}{l}\text { No } \\
(n=82)\end{array}$ & \\
\hline \multicolumn{4}{|c|}{ Birth Control Use (self or partner) } \\
\hline Yes & $39(83.0)$ & $36(43.9)$ & $<0.001$ \\
\hline No & $8(17.0)$ & $46(56.1)$ & \\
\hline \multicolumn{4}{|c|}{ Knowledge that Copper IUD can be used as EC } \\
\hline Yes & $8(17.8)$ & $8(10.0)$ & $<0.001$ \\
\hline No & $37(82.1)$ & $72(90.0)$ & \\
\hline
\end{tabular}

${ }^{\mathrm{a}}$ The results reported are frequency counts with percentages in parenthesis
Participants were provided with an educational piece at the end of the survey, which stated: "The Intrauterine Device (IUD) is a small T-shaped device about 1 inch long. It is a very effective method of birth control that your health care provider inserts into the uterus. Nonhormonal (copper) and hormonal versions are available. The non-hormonal or copper version can be left in place for up to 10 years. The hormonal version can be left in place for up to 3 to 5 years." They were subsequently asked if they would use and/or recommend the IUD as a form of birth control. Approximately half of the participants remained neutral despite receiving the education

Table 4 Awareness vs. Knowledge Assessment of Utility of IUDs as

\begin{tabular}{|c|c|c|c|}
\hline & \multicolumn{2}{|c|}{ Have you heard of the intrauterine device (IUD)? } & \multirow[t]{2}{*}{ P Value } \\
\hline & $\begin{array}{l}\text { Yes } \\
(n=86)\end{array}$ & $\begin{array}{l}\text { No } \\
(n=40)\end{array}$ & \\
\hline \multicolumn{4}{|c|}{ The copper IUD is inserted into the uterus. } \\
\hline True & $51(59.3)$ & $6(15.0)$ & $<0.001$ \\
\hline False & $3(3.5)$ & $0(0)$ & \\
\hline I don't know. & $32(37.2)$ & $34(85.0)$ & \\
\hline \multicolumn{4}{|c|}{ Insertion of the copper IUD can cause cramping. } \\
\hline True & $35(41.2)$ & $3(7.5)$ & $<0.001$ \\
\hline False & $4(4.7)$ & $1(2.5)$ & \\
\hline I don't know. & $46(54.1)$ & $36(90.0)$ & \\
\hline \multicolumn{4}{|c|}{ The copper IUD prevents pregnancy when used appropriately. } \\
\hline True & $62(72.9)$ & $6(15.0)$ & $<0.001$ \\
\hline False & $2(2.4)$ & $2(5.0)$ & \\
\hline I don't know. & $21(24.7)$ & $32(80.0)$ & \\
\hline \multicolumn{4}{|c|}{ The copper IUD does not protect against sexually transmitted diseases. } \\
\hline True & $52(61.2)$ & $5(12.5)$ & $<0.001$ \\
\hline False & $5(5.9)$ & $2(5.0)$ & \\
\hline I don't know. & $28(32.9)$ & $33(82.5)$ & \\
\hline \multicolumn{4}{|c|}{ Irregular Bleeding is a side effect of the copper IUD } \\
\hline True & $37(44.1)$ & $3(7.5)$ & $<0.001$ \\
\hline False & $2(2.4)$ & $2(5.0)$ & \\
\hline I don't know. & $45(53.5)$ & $35(87.5)$ & \\
\hline \multicolumn{4}{|c|}{ The copper IUD can be used as a method of EC. } \\
\hline True & $12(14.1)$ & $4(10.0)$ & $<0.001$ \\
\hline False & $35(41.2)$ & $2(5.0)$ & \\
\hline I don't know. & $38(44.7)$ & $34(85.0)$ & \\
\hline \multicolumn{4}{|c|}{ You can use the copper IUD even if you've never had a baby. } \\
\hline True & $50(59.5)$ & $3(7.5)$ & $<0.001$ \\
\hline False & $3(3.6)$ & $1(2.5)$ & \\
\hline I don't know. & $31(36.9)$ & $36(90.0)$ & \\
\hline \multicolumn{4}{|c|}{ The copper IUD does not require daily reminders. } \\
\hline True & $52(61.2)$ & $5(12.5)$ & $<0.001$ \\
\hline False & $4(4.7)$ & $0(0)$ & \\
\hline I don't know. & $29(34.1)$ & $35(87.5)$ & \\
\hline
\end{tabular}

${ }^{\mathrm{a}}$ The results reported are frequency counts with percentages in parenthesis 
and some provided feedback on their decisions. Some participants listed common misconceptions as their reasons against choosing the IUD in their comment section of the survey. Some participants commented that they still did not have enough knowledge regarding the IUD in general and expressed reluctance to use it or recommend to others.

Participants were also provided with information regarding the copper IUD's function as form of EC. The statement "Studies have shown that the copper IUD is the most effective form of emergency contraception" was provided to the participants. They were subsequently asked if they would use or recommend the copper IUD as a form of EC. Almost half of the participants remained neutral despite receiving this information and some provided feedback on their decisions. The provided feedback did reveal that some participants did feel like the copper IUD would be a good option for EC after reading the information about the efficacy of the copper IUD.

\section{Discussion}

The results of this study showed that the knowledge base of participants in this study was significantly lacking. When participants were asked about specific IUD contraceptive information, a majority of respondents answered with "I don't know". This indicated a gap in the information being presented to this population. Though many claim awareness of the IUD, they failed to understand its function or its side effects. The results of this study were similar to the 2015 study performed by Marshall et al., which found that awareness and perceived knowledge of IUDs among males was low in comparison to condoms and birth control pills [12]. However, the same study had also shown that young men's perceived knowledge of IUDs was lower than their objective knowledge, whereas this study reveals that most males did not know much about the utility of the IUD [12].

Our results revealing only $2.6 \%$ of our participants using IUDs mirrored previous studies that demonstrated the low utilization of IUDs in the United States (3-5, and). All of the study participants who had a history of EC use had used emergency contraception in the oral pill formulation. A significant percentage of participants were unaware that the IUD could also be used as a form of EC. Efficacy should play a role in satisfaction with one's birth control; however, if EC is being accessed, the birth control method may be clearly ineffective. This was consistent with previous studies that have shown that the use of the copper IUD as EC remained limited [6].

Most participants remained "neutral" after reviewing an education section of the survey on the efficacy of the copper IUD as a contraceptive method. However, the positive responses to the education section of the survey on the efficacy of the copper IUD as a good EC option confirmed the importance of distributing factual written information to adolescents and young adults in order to expand knowledge. Provision of written information should create an opportunity to facilitate this reproductive health decision-making process by stimulating a discussion with their health care provider or health educator.

One strength of this study is that it included male as well as female participants. Another strength of this study is that the survey included questions regarding sexual orientation and gender of sexual partners. These variables have not usually been included in earlier contraception studies.

Our study is not without limitations. One limitation of this study was the small participant size. Our study population was also primarily of one geographical region located in a greater urban community. Further, our survey was only offered in English and required participants to be able to read in English. With a larger and more diverse study population, we might determine other factors involved in the reproductive health decision-making process.

\section{Conclusion}

Barriers continue to exist for adolescents and young adults when it comes to contraception - these include, but are not limited to: access, awareness, and knowledge. The IUD remains the first-line contraceptive method offered as recommended by ACOG and the AAP. This study shows that despite awareness about the IUD, adequate knowledge is lacking among adolescents and young adults regarding its utility. The results of this study highlight the importance of committed and consistent comprehensive contraceptive education interventions for adolescent and young adult patients. Future research should include an assessment of the sources of information used by adolescents and young adults to attain their contraceptive knowledge as well as whether or not they received sexual health education as part of their school curricula. Enhanced contraceptive options counseling can help providers ensure that their patients make well-informed decisions about contraceptive methods, thus improving their quality of life.

\section{Abbreviations \\ AAP: American Academy of Pediatrics; ACOG: American College of Obstetrics and Gynecology; AYA: Adolescents and young adults; EC: Emergency contraception; IUD: Intrauterine device; OCP: Oral contraception pill(s)}

\section{Acknowledgements}

Not applicable.

Ethics approval and consent to participants

The study design received Northwell Health Institutional Review Board (IRB) approval prior to implementation. IRB \#: 17-0802. 


\section{Consent for publications}

Not applicable.

\section{Authors' contributions}

$A S, A L$, and EM were responsible for data collection and analyzed and interpreted the patient data. SJ assisted in data collection. SD performed the statistical analysis. All authors were involved in the conceptualization of this study. All authors read and approved the final manuscript.

\section{Funding}

No funding was received.

\section{Availability of data and materials}

The datasets during and/or analyzed during the current study available from the corresponding author on reasonable request.

\section{Competing interests}

The authors declare that they have no competing interests.

\section{Author details}

'Department of Pediatrics, Staten Island University Hospital, Staten Island, NY, USA. ${ }^{2}$ Department of Developmental Medicine, Boston Childrens Hospital, Boston, MA, USA. ${ }^{3}$ Division of Adolescent Medicine, Staten Island University Hospital, Staten Island, NY, USA. ${ }^{4}$ Department of Research, Staten Island University Hospital, Staten Island, NY, USA. ${ }^{5}$ Biostatistics Unit, Feinstein Institute for Medical Research, Staten Island University Hospital, Staten Island, NY, USA.

Received: 21 February 2020 Accepted: 8 December 2020

Published online: 05 January 2021

\section{References}

1. ACOG Committee Opinion No. 392. Intrauterine device and adolescents. Obstet Gynecol. 2007;110:1493-5.

2. Blythe MJ, Diaz A. Contraception and adolescents. Pediatrics. 2007;120:113548.

3. Alton TM, Brock GN, Yang D, Wilking DA, Hertweck P, Loveless MB. Retrospective review of intrauterine device in adolescent and young women. J Pediatr Adolesc Gynecol. 2012;25:195-200.

4. Mestad R, Securar G, Allsworth JE, Madden T, Zhao Q, Peipert JF. Acceptance of long-acting reversible contraceptive methods by adolescent participants in the contraceptive CHOICE project. Contraception. 2011;84: 493-8.

5. Godfrey EM, Memmel LM, Neustadt A, Shah M, Nicosia A, Moorthie M, Gilliam M. Intrauterine contraception for adolescents aged 14-18 years: a multicenter randomized pilot study of Levonorgestrel-releasing intrauterine system compared to the copper T380A. Contraception. 2010;81:123-7.

6. Seetharaman S, Yen S, Ammerman SD. Improving adolescent knowledge of emergency contraception: challenges and solutions. Open Access J Contracept. 2016;7:161-73. https://doi.org/10.2147/OAJC.S97075.

7. Whitaker AK, Johnson LM, Harwood B, Chiappetta L, Creinin MD, Gold MA. Adolescent and young adult women's knowledge of and attitudes toward the intrauterine device. Contraception. 2008;78(3):211-7.

8. Daniels $\mathrm{K}$ et al. Current contraceptive use and variation by selected characteristics among women aged 15-44: United States, 2011-2013, National Health Statistics Reports, 2015, No. 86

9. Lindberg L, Santelli J, Desai S. Understanding the decline in adolescent fertility in the United States, 2007-2012. J Adolesc Health. 2016; https://doi. org/10.1016/j.jadohealth.2016.06.024.

10. Higgins J.A. (2017). Pregnancy ambivalence and long-acting reversible contraceptive (LARC) use among young adult women: a qualitative study. Perspectives on sexual and reproductive health, 49(3):TK.

11. Frost JJ, Lindberg LD, Finer LB. Young adults' contraceptive knowledge, norms and attitudes: associations with risk of unintended pregnancy. Perspect Sex Reprod Health. 2012;44(2):107-16.

12. Marshall CJ, Gomez AM. Young men's awareness and knowledge of intrauterine devices in the United States. Contraception. 2015;92(5):494-500.

\section{Publisher's Note}

Springer Nature remains neutral with regard to jurisdictional claims in published maps and institutional affiliations.

\section{Ready to submit your research? Choose BMC and benefit from:}

- fast, convenient online submission

- thorough peer review by experienced researchers in your field

- rapid publication on acceptance

- support for research data, including large and complex data types

- gold Open Access which fosters wider collaboration and increased citations

- maximum visibility for your research: over $100 \mathrm{M}$ website views per year

At BMC, research is always in progress.

Learn more biomedcentral.com/submissions 